\title{
Exploring the burden of fatal drowning and data characteristics in three high income countries: Australia, Canada and New Zealand
}

\author{
Amy E. Peden ${ }^{1,2^{*}}$, Richard C. Franklin ${ }^{1,2}$ (D) and Tessa Clemens ${ }^{3}$ (D)
}

\begin{abstract}
Background: Drowning is a leading and preventable cause of death that has suffered an attention deficit. Improving drowning data in countries would assist the understanding of the full extent and circumstances of drowning, to target interventions and evaluate their effectiveness. The World Health Organization identifies data collection as a key strategy underpinning effective interventions. This study compares unintentional fatal drowning data collection, management and comparison using the databases of Australia, Canada and New Zealand.
\end{abstract}

Methods: Cases of fatal unintentional drowning between 1-January-2005 and 31-December-2014 were extracted. Cases were combined into a single dataset and univariate and chi square analysis $(p<0.01)$ were undertaken. Location and activity variables were mapped and combined. Variables consistently collected across the three countries were compared to the ILCOR Drowning Data Guideline. The authors also recommend variables for a minimum core dataset.

Results: Of 55 total variables, 19 were consistent and 13 could be compared across the three databases. When mapped against the ILCOR Drowning Data Guideline, six variables were consistently collected by all countries, with five compared within this study. The authors recommend a minimum core dataset of 11 variables including age, sex, location, activity, date of incident, and alcohol and drug involvement).

There were 8176 drowning deaths (Australia 34.1\%, Canada 55.9\%, New Zealand 9.9\%). All countries achieved reductions in crude drowning rates (Australia - 10.2\%, Canada - 20.4\%, New Zealand - 24.7\%). Location and activity prior to drowning differed significantly across the three countries. Beaches $\left(X^{2}=1151.0 ; p<0.001\right)$ and ocean/ harbour locations $\left(X^{2}=300.5 ; \mathrm{p}<0.001\right)$ were common in Australia and New Zealand, while lakes/ponds $\left(X^{2}=826.5\right.$; $p<0.001)$ and bathtubs $\left(X^{2}=27.7 ; p<0.001\right)$ were common drowning locations in Canada. Boating prior to drowning was common in Canada $\left(X^{2}=66.3 ; p<0.001\right)$.

Conclusions: The comparison of data across the three countries was complex. Work was required to merge categories within the $20 \%$ of variables collected that were comparable, thus reducing the fidelity of data available. Data sources, collection and coding varied by country, with the widest diversity seen in location and activity variables. This study highlights the need for universally agreed and consistently applied categories and definitions to allow for global comparisons and proposes a core minimum dataset.

Keywords: Drowning, Epidemiology, Coding systems, Public health, Mortality

\footnotetext{
* Correspondence: apeden@rlssa.org.au

${ }^{1}$ Royal Life Saving Society - Australia, PO Box 558, Broadway, New South Wales, Australia

${ }^{2}$ College of Public Health, Medical and Veterinary Sciences, James Cook University, Townsville, Queensland, Australia

Full list of author information is available at the end of the article
}

(c) The Author(s). 2019 Open Access This article is distributed under the terms of the Creative Commons Attribution 4.0 International License (http://creativecommons.org/licenses/by/4.0/), which permits unrestricted use, distribution, and reproduction in any medium, provided you give appropriate credit to the original author(s) and the source, provide a link to the Creative Commons license, and indicate if changes were made. The Creative Commons Public Domain Dedication waiver (http://creativecommons.org/publicdomain/zero/1.0/) applies to the data made available in this article, unless otherwise stated. 


\section{Background}

Drowning is a leading and preventable cause of death that has suffered an attention deficit, due in part to a lack of quality data. The development of drowning prevention interventions requires data systems that provide detailed and nuanced information on the circumstances of drowning. The current estimate, acknowledged as an underreport of the true burden of drowning [1-5], is 372,000 fatal drownings globally per year [6]. Improving drowning data in countries has been identified as a key strategy by the World Health Organization (WHO) to better understand the full extent and circumstances of drowning, to target interventions and evaluate their effectiveness [7].

The use of International Classification of Diseases (ICD) codes to explore drowning is a common approach but provides a limited understanding of causal factors, impacting the development and reporting on the effectiveness of prevention strategies [8]. ICD-10 coding provides limited information on drowning location and provides no information on activity. Drowning deaths due to water transportation incidents, and as a result of flooding are also commonly excluded from global estimates [1].

The circumstances leading to drowning are complex. In high-income countries people interact with water primarily for recreation [9-13]. By contrast, drowning in lowand middle-income countries often occurs as a result of interactions with water due to daily life or occupational endeavours [14-16]. Prevention strategies, must therefore differ to suit the environment and the unique causal factors contributing to drowning risk in different contexts.

The comparison of data collation and database management methodologies has been used in other areas of research to work towards improving health [17-20]. Cross-country comparison of drowning data has also been conducted previously, with capture based only on ICD-10 codes [21]. Such comparisons are valuable to identify strengths, weaknesses and commonalities in data collation and coding, as well as enable sharing of successful interventions, across countries with similar drowning burden and risk factors. However the ability to compare relies on consistency of coding and/or transparency of definitions and frameworks used to collate and code data to allow for mapping. There currently exists no definitive coding framework for drowning data. The ILCOR Advisory Statement - 2015 Revised UtsteinStyle Recommended Guidelines for Reporting of Data From Drowning-Related Resuscitation [22] (henceforth referred to as the ILCOR Drowning Data Guideline), through an established consensus process, proposes updated guidelines for reporting data from studies of resuscitation from drowning. These Guidelines can be considered a useful starting point for developing a minimum core dataset for drowning suitable for use in countries with and without death registry, although the
Guidelines are used for improving clinical outcomes rather than prevention.

Death investigation is vital to understanding the epidemiology of drowning, due to the rich detail that can be derived from case documentation [23]. Australia, Canada and New Zealand, through the benefit of wellresourced death registry and coronial systems, have three of the best unintentional fatal drowning databases in the world. All are high-income, English speaking countries, with similar culture and population distribution. All have Indigenous populations at increased risk of drowning (Table 1).

This study aims to examine three of the most comprehensive fatal drowning databases in the world to: (1) describe data collection and coding; and (2) compare crude fatal drowning rates, demographics and risk factors.

\section{Methods}

For the purposes of this study, only deaths where unintentional drowning was indicated as a primary or contributing cause of death were included. Excluded were all other water-related fatalities (i.e. spinal injury, hypothermia) where drowning was not a contributing factor. The process for the collection and collation of data in each of the three countries is discussed below.

\section{Australia}

Data on all unintentional fatal drownings in Australia were sourced from the Royal Life Saving National Fatal Drowning Database [24] (the Australian database). All cases in the Australian database are extracted from the National Coronial Information System (NCIS), an online repository of all deaths investigated by a coroner. The NCIS provides rich detail identified using medico-legal investigation [23] made available in the form of up to four documents: a coroner's report (or inquest report should an inquest occur), an autopsy report; a toxicology report and a police report. The data available on the NCIS varies (e.g. any combination of the four reports mentioned above) and relies on documentation being uploaded electronically onto the NCIS online system.

The Australian database also uses a triangulation method to source drowning data through year-round monitoring of media (print, broadcast, online) police reports, Child Death Review Team reports, social media and reports from lifesaving clubs [1].

Data collected (where available) includes: demographics (e.g. age, sex, residence, indigenous status, ethnicity etc), cause of death, circumstances (e.g. time of day, day of week, season, year, location, activity etc), autopsy and toxicology information (e.g. presence and type of preexisting and contributory medical conditions, and drug and alcohol blood concentrations), as well as supplementary information on drowning related issues (e.g. 


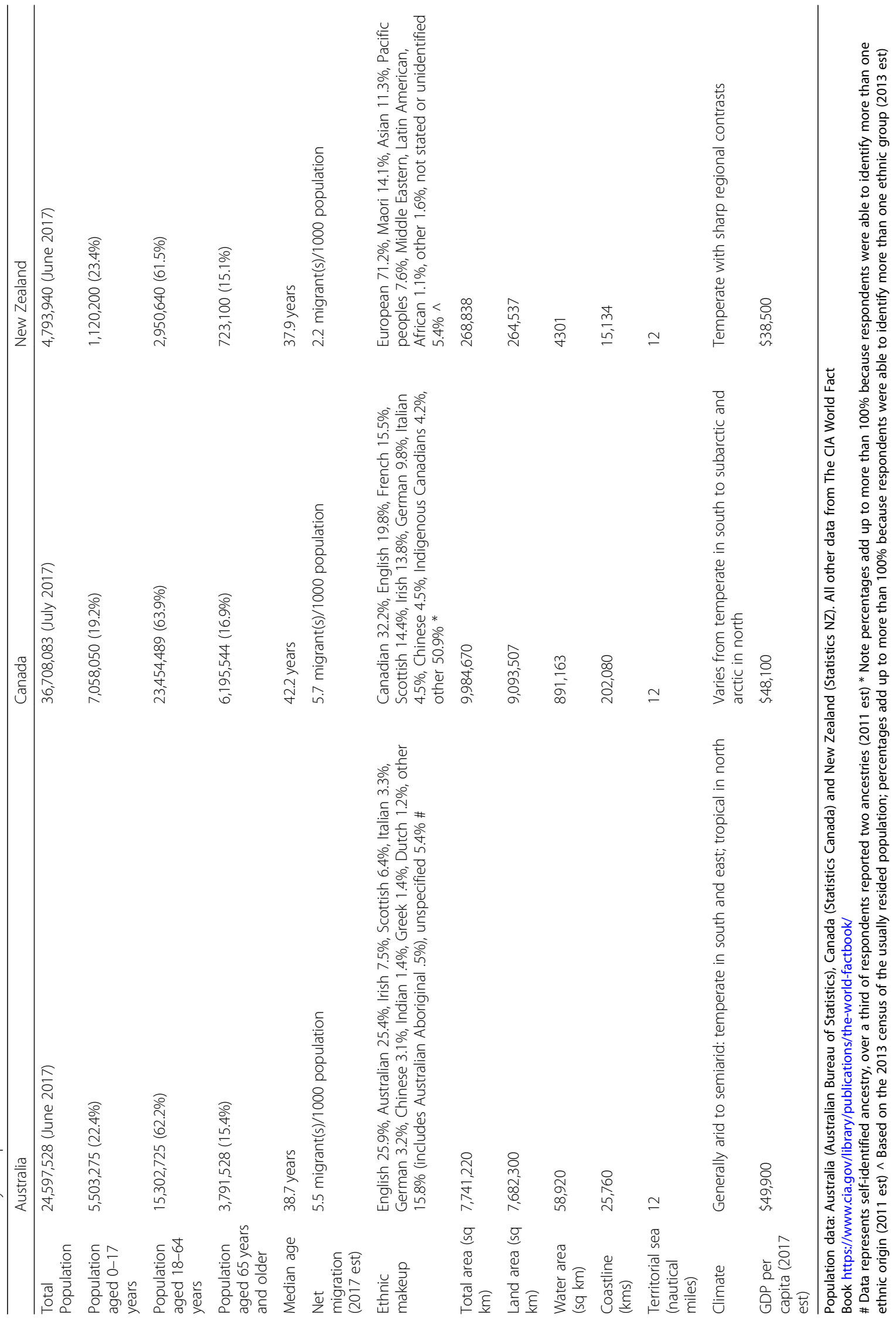


lifejacket use, supervision, swimming skills). The Australian database includes all unintentional fatal drowning cases in Australia from 1-July-2002 and reports drowning on an annual financial year basis through the Royal Life Saving National Drowning Report [25] and a range of research outputs.

Data is transposed from the various sources into an IBMSPSS database for analysis. Data is correct as at 01December- 2017.

\section{Canada}

Data on all unintentional fatal drowning incidents that occurred in Canada were obtained from the Drowning Prevention Research Centre (DPRC) database (the Canadian database). The Canadian database contains anonymized data related to all unintentional water-related fatalities that occur in Canada.

As part of an on-going water-related fatality surveillance project, trained local data collectors enter each of the provincial and territorial Coroner's and Medical Examiner's offices annually to conduct structured reviews of the files for all unintentional water-related deaths. Water-related death is defined as death from drowning [26], as well as all non-drowning death (e.g. hypothermia, trauma) involving water occurring while undertaking a range of activities. Although the Canadian database includes all unintentional water-related deaths, only those deaths where drowning was a primary or contributing cause of death were accessed for this study.

A structured questionnaire is used to collect data on demographics; cause of death; activity type and purpose of activity; and personal, equipment and environmental risk factors. The questionnaire was initially developed in 1991, and has been reviewed and revised approximately every 5years since then to ensure the reliability and comprehensiveness of the collected data. Data sources contained in the Coroner's and Medical Examiner's files vary by province and territory. Common documents found in the files and used to extract data include: Coroner's or Medical Examiner's investigation statement, death certificate, police report, hospital records, postmortem/autopsy report, and toxicology report.

Data collectors fill out paper questionnaires that are reviewed by both a local and national project manager. When errors or inconsistencies are identified, the relevant file is re-opened and issues are addressed. Concerns of admissibility related to intentionality or cause of death are forwarded to a consultant epidemiologist and coroner for review and decision. Data entry of final validated cases occurs at the national level, and each case is subsequently reviewed for data entry errors.

The Canadian surveillance system utilises on-going review of media clippings to monitor current drowning trends. Water-related fatality cases identified in the media are entered into the database immediately after they occur. When cases from the Coroner's and Medical Examiner's files are entered into the database, they are automatically linked to the corresponding media file. This process assists with validation and verification of the cases and data.

Data is correct as at 17-January-2018.

\section{New Zealand}

Water Safety New Zealand (WSNZ) are responsible for collating and maintaining details on all fatal drowning records in New Zealand (NZ). These records are kept in DrownBase $^{\mathrm{Tw}}$ which is the official database of WSNZ (the New Zealand database) [27]. The New Zealand database has been developed using Microsoft Access. The New Zealand database was developed in 1994 and contains records of all drowning deaths that have occurred in New Zealand's waterways since 1 January 1980 and all water related hospitalisations requiring a stay in hospital of longer than $24 \mathrm{~h}$ since 2003.

Data is collated by WSNZ through partnerships with the New Zealand Police, the Coronial Services of the Ministry of Justice and the New Zealand Health Information Service (NZHIS). In order to maintain the integrity of the data, and to ensure WSNZ is accurately presented to the New Zealand public, a set protocol has been established. The protocol covers data collection and entry.

Fatal drowning data is initially collected from the New Zealand Police via "Drown reports and media reports. Follow up collection of data from Coroners' reports, and Ministry of Health information assists in completing the data collection procedure.

The New Zealand database captures and records fatal drowning data across a range of fields. Where possible pre -existing lists are used, however some data is recorded by using a free text entry field, (eg. Family Name). All preexisting lists are supported by comprehensive descriptors and metadata.

Preventable fatalities include recreational and nonrecreational drowning deaths. They do not include those fatalities classified as 'other' (arising as a result of road or air vehicle accidents, homicide, suicide or of unknown origin) as these are not considered applicable to the prevention and rescue efforts of the water safety sector.

The word 'intent' could describe homicide or suicide. Unknown origin is a description used when we don't how/why person ended up in the water.

Data is correct as at 29-November-2017.

\section{Country-comparisons}

A subset of each country's databases, (i.e. all fatal unintentional drowning cases for the 10 calendar year period 1January-2005 to 31-December-2014), were extracted. The variables collected by each country were mapped (Table 2). 
Table 2 Variables mapped across the three databases, Australia, Canada and New Zealand

\begin{tabular}{|c|c|c|c|c|c|c|}
\hline Variable & Australia & Canada & New Zealand & $\begin{array}{l}\text { Included in } \\
\text { study }(\sqrt{ })\end{array}$ & $\begin{array}{l}\text { Included in Utstein } \\
\text { Guidelines }(\sqrt{ })[23]\end{array}$ & $\begin{array}{l}\text { Recommended core } \\
\text { variables }(\sqrt{ })\end{array}$ \\
\hline Case ID & $x$ & $x$ & $x$ & & \multirow[t]{4}{*}{$\sqrt{ }$ (Victim Identifier) } & \multirow[t]{4}{*}{$\sqrt{ }$} \\
\hline Data source & & & $x$ & & & \\
\hline $\begin{array}{l}\text { Province, region, state/territory of drowning } \\
\text { incident }\end{array}$ & $x$ & $x$ & $x$ & & & \\
\hline Incident year & $x$ & $x$ & $x$ & $\sqrt{ }$ & & \\
\hline Date of incident (DD-MM-YYYY) & $x$ & $x$ & $x$ & $\sqrt{ }$ & \multirow{7}{*}{$\begin{array}{l}\sqrt{ } \text { (Incident date and time } \\
\text { of day) }\end{array}$} & \multirow[t]{2}{*}{$\sqrt{ }$} \\
\hline Time of incident & $x$ & & & & & \\
\hline Primary Cause of Death & $x$ & $x$ & & & & \multirow[t]{5}{*}{$\sqrt{ }$} \\
\hline Contributory cause(s) of death & $x$ & $x$ & & & & \\
\hline Incident synopsis & $x$ & $x$ & $x$ & & & \\
\hline Incident type & & & $x$ & & & \\
\hline Inquest number & & & $x$ & & & \\
\hline Age in years & $x$ & $x$ & $x$ & & \multirow[t]{2}{*}{$\sqrt{ }$ (Age -Birthdate) } & \multirow[t]{2}{*}{$\sqrt{ }$} \\
\hline Age group & $x$ & $x$ & $x$ & $\sqrt{ }$ & & \\
\hline Sex & $x$ & $x$ & $x$ & $\sqrt{ }$ & $\sqrt{ }(\operatorname{Sex})$ & $\sqrt{ }$ \\
\hline Ethnicity & $x$ & & $x$ & & \multirow{25}{*}{$\begin{array}{l}\sqrt{ } \text { (Race and ethnic } \\
\text { categories) }\end{array}$} & \multirow[t]{12}{*}{$\sqrt{ }$} \\
\hline First Nations Peoples & $x$ & $x$ & $x$ & $\sqrt{ }$ & & \\
\hline Residential status & $x$ & $x$ & $x$ & $\sqrt{ }$ & & \\
\hline Population Density (Urban/Rural) & $x$ & $x$ & & & & \\
\hline Location geographic & $x$ & $x$ & $x$ & & & \\
\hline Water Depth & & $x$ & & & & \\
\hline Distance from Safety & & $x$ & & & & \\
\hline Wave conditions & & $x$ & & & & \\
\hline Water current & & $x$ & & & & \\
\hline Ice conditions & & $x$ & & & & \\
\hline Water Temp Range & & $x$ & & & & \\
\hline Light conditions & & $x$ & & & & \\
\hline Aquatic location category & $x$ & $x$ & $x$ & $\sqrt{ }$ & & $\sqrt{ }$ \\
\hline Activity prior to drowning & $x$ & $x$ & $x$ & $\sqrt{ }$ & & $\sqrt{ }$ \\
\hline $\begin{array}{l}\text { Purpose of Activity (Daily Living, Recreational/Non- } \\
\text { recreational) }\end{array}$ & & $x$ & $x$ & & & \\
\hline Primary recreational activity & & $x$ & & & & \\
\hline Secondary recreational activity & & $x$ & & & & \\
\hline Daily Living Activity & & $x$ & & & & \\
\hline Occupational Activity & & $x$ & & & & \\
\hline Boating Causes & & $x$ & & & & \\
\hline Type of Boating Incident & & $x$ & & & & \\
\hline Watercraft Type & $x$ & $x$ & & & & \\
\hline Multiple Fatality Event - Yes/No/Unknown & $x$ & $x$ & $x$ & $\sqrt{ }$ & & \\
\hline If yes, number of fatalities & $x$ & & $x$ & & & \\
\hline Lifejacket wear & $x$ & $x$ & $x$ & $\sqrt{ }$ & & \\
\hline Medical Condition (pre-existing, chronic) & $x$ & $x$ & $x$ & $\sqrt{ }$ & $\sqrt{ }$ (Preexisting illness) & \\
\hline Hypothermia & & & $x$ & & & \\
\hline Victim Alcohol Involvement & $x$ & $x$ & $x$ & $\sqrt{ }$ & & $\sqrt{ }$ \\
\hline
\end{tabular}


Table 2 Variables mapped across the three databases, Australia, Canada and New Zealand (Continued)

\begin{tabular}{|c|c|c|c|c|c|c|}
\hline Variable & Australia & Canada & New Zealand & $\begin{array}{l}\text { Included in } \\
\text { study }(\sqrt{ })\end{array}$ & $\begin{array}{l}\text { Included in Utstein } \\
\text { Guidelines }(\sqrt{ })[23]\end{array}$ & $\begin{array}{l}\text { Recommended core } \\
\text { variables }(\sqrt{ })\end{array}$ \\
\hline Blood Alcohol Content (BAC) & $x$ & $x$ & & & & \\
\hline Alcohol Involvement by Companions & $x$ & $x$ & & & & \\
\hline Victim Drug Involvement & $x$ & $x$ & $x$ & $\sqrt{ }$ & & $\sqrt{ }$ \\
\hline Type of drug (legal, not legal) & $x$ & $x$ & & & & \\
\hline Type of drug (name) & $x$ & $x$ & & & & \\
\hline Victim swimming ability & $x$ & $x$ & & & & \\
\hline Resuscitation enacted - Yes/No/Unknown & & $x$ & $x$ & & & $\sqrt{ }$ \\
\hline Beach Patrolled & & & $x$ & & & \\
\hline Pool Fencing & $x$ & $x$ & $x$ & & & \\
\hline Supervision of children & $x$ & $x$ & & & & \\
\hline Commercial & & & $x$ & & & \\
\hline Occupation & & & $x$ & & & \\
\hline Purpose & & & $x$ & & & \\
\hline
\end{tabular}

Where all three countries collected the variable, it was copied across into a master IBMSPSS V20 [28] dataset. A new variable was added denoting the country in which the drowning occurred.

Location and activity codes as collected by each country were copied into the master dataset. They were then mapped across the three countries and similar categories were combined (Table 3) (Table 4). An amalgam of each country's definitions were used to construct the definitions found in Tables 3 and 4.

Alcohol refers to where alcohol was present (yes, no, unknown) rather than blood alcohol concentrations (BAC). Drugs (yes, no, unknown) refers to both legal (e.g. prescription) and illicit (illegal) drug consumption. International tourists are those people who were known to reside in a different country from the country where they drowned. A multiple fatality event (MFE) refers to a single drowning incident where more than one person drowned. Lifejacket wear was only collected and analysed for boating drowning incidents $(n=2039)$. Indigenous peoples is used as a catch-all term to refer to Maori, Australian First Nations Peoples and Canada's Indigenous populations.

Variables collected were compared to those recommended in the ILCOR Drowning Data Guideline [22]. The authors also make recommendations for those variables to be included in a minimum core dataset for countries compiling drowning databases with a view to enabling better comparison of drowning data across countries and contributing to drowning prevention.

\section{Statistical analysis}

Nineteen of the 55 variables made available were consistently reported by all three countries and 13 were able to be compared in this study. There were six variables consistently collected, but not compared within this study: region/location/state or territory of drowning incident within a country, incident synopsis, age in years, location geographic and pool fencing. Region of drowning incident, incident synopsis and location geographic all varied and were not able to be compared between countries. Age in years was used to calculate age group for ease of analysis. Pool fencing was not included within the scope of the study as it is a drowning prevention strategy most suitable for children under five and as such, was not comparable across all age groups.

Univariate and chi square analysis was undertaken. Statistical significance was deemed $p<0.001$. Non-parametric testing was also conducted using the proportional basis of the population as the assumed outcome numbers. Crude annual drowning rates per 100,000 population and 10 year averages were calculated for each country using population data sourced from national statistics organisations [29-31]. Drownings of international tourists (without a residential address) were removed from the numerator when calculating rates as they were not represented in the population estimates. Those cases where residential status was unknown were retained.

\section{Results}

Of the 55 variables made available for this study, 19 were consistent across all three databases. Consistently collected variables included date of incident, age group, sex, residential status, category of aquatic location, activity prior to drowning and if the drowning occurred during a MFE, among others (Table 2). When mapped against the ILCOR Drowning Data Guideline [22], 6 variables were consistently collected by all countries, with five being able to be compared within this study. The five compared 
Table 3 Location categories and definitions

\begin{tabular}{|c|c|c|c|c|}
\hline Manuscript Category & Definition/Explanation & Australian label & Canadian label & New Zealand label \\
\hline Bathtub & $\begin{array}{l}\text { The victim was in a man-made tub or shower } \\
\text { primarily used for personal bathing, generally } \\
\text { emptied after use. Includes showers and in- } \\
\text { door spa baths. }\end{array}$ & Bathtub & Bathtub & Bath \\
\hline Beach & Sandy and rocky foreshore to coastal waters & Beach, Coastal Rocks & & $\begin{array}{l}\text { Surf Beach, Calm Water Beach, } \\
\text { Rocky Foreshore }\end{array}$ \\
\hline Lake/Pond & $\begin{array}{l}\text { A body of water, of variable size, which is } \\
\text { surrounded by land. }\end{array}$ & Lake/Dam/Lagoon, Pond & Lake or Pond & Pond, Lake \\
\hline Ocean/Harbour & $\begin{array}{l}\text { An open expanse of coastal water, } \\
\text { characterised by tides, that is generally } \\
\text { accessed via a jetty or watercraft. Excludes } \\
\text { the sandy/rocky shore of a beach entry. }\end{array}$ & Ocean/Harbour & Ocean & $\begin{array}{l}0-1 \mathrm{~km} \text { From Shore, } 1-5 \mathrm{~km} \\
\text { From Shore, } 5+\mathrm{km} \text { From Shore, } \\
\text { Marina, Harbour, River/Harbour } \\
\text { Bar, Estuary }\end{array}$ \\
\hline Other & Locations that do not fit into existing codes. & $\begin{array}{l}\text { Other, Fishpond, Irrigation } \\
\text { Channel, Drain }\end{array}$ & $\begin{array}{l}\text { Other, Marsh/ } \\
\text { Bog/Swamp }\end{array}$ & $\begin{array}{l}\text { Buckets, Drain, Other Waters, } \\
\text { Domestic Location }\end{array}$ \\
\hline River & $\begin{array}{l}\text { A natural/fresh waterway fed by other bodies } \\
\text { of water. Can vary in water flow, length, } \\
\text { width and depth. }\end{array}$ & River/Creek/Stream & Flowing Water & Streams, Floods \\
\hline Swimming Pool & $\begin{array}{l}\text { A permanent or temporary excavation, } \\
\text { structure or vessel that is solely intended, or } \\
\text { principally used, for human aquatic activity. } \\
\text { Includes portable, above and below ground } \\
\text { pools in homes, hotels/motels and public } \\
\text { areas. Includes outdoor spas. }\end{array}$ & $\begin{array}{l}\text { Swimming Pool - Home, } \\
\text { Swimming Pool - Public, } \\
\text { Swimming Pool - } \\
\text { Temporary Residence }\end{array}$ & $\begin{array}{l}\text { Pool, Hot tub/ } \\
\text { Whirlpool }\end{array}$ & $\begin{array}{l}\text { Thermal Pools, Spa Pools, } \\
\text { School Pools, Public Pools, } \\
\text { Portable Pools, Hotel/Motel } \\
\text { Pools, Home Pools }\end{array}$ \\
\hline Unknown & Location of drowning incident is not known & Unknown & Unknown & Unknown \\
\hline
\end{tabular}

within the study were date of incident (referred to in ILCOR Data Guideline as incident date and time of day); age (age - birthdate); sex (sex); first nation's peoples (race and ethnic categories); and medical condition (pre-existing illness). The variable of case ID (victim identifier) was consistently collected but not able to be compared (Table 2).

The authors recommend a minimum core dataset of 11 variables. The recommended variables are: Case ID; date of incident; primary cause of death; age in years

Table 4 Activity categories and definitions

\begin{tabular}{|c|c|c|c|c|}
\hline Manuscript Category & Definition/Explanation & Australian label & Canadian label & New Zealand label \\
\hline Aquatic activity & $\begin{array}{l}\text { The victim was in the water } \\
\text { and intended to be there. }\end{array}$ & $\begin{array}{l}\text { Swimming and } \\
\text { Recreating, } \\
\text { Diving, Fishing, } \\
\text { Jumped In }\end{array}$ & Aquatic activity & $\begin{array}{l}\text { Free diving, Snorkelling, Scuba Diving, Diving/ } \\
\text { Jumping, Net fishing, Commercial fishing, } \\
\text { Angling, Shellfishing, Swimming, Boogie } \\
\text { boarding, board riding, Tubing, canyoning, }\end{array}$ \\
\hline Bathing & $\begin{array}{l}\text { Submerging/immersing the body in } \\
\text { water for the purposes of relaxation or } \\
\text { cleaning. Generally not vigorous activity. }\end{array}$ & Bathing & Bathing & Bathing \\
\hline Boating & $\begin{array}{l}\text { Using a powered or unpowered vessel } \\
\text { for the purposes of recreation or } \\
\text { transportation. }\end{array}$ & $\begin{array}{l}\text { Boating, } \\
\text { Watercraft }\end{array}$ & Boating & $\begin{array}{l}\text { Windsurfing, Under } 4 \text { m, Trailer Sailor, Sailing } \\
\text { Dinghy, Rowing craft/Dinghy, Rafting, Over } 4 \\
\text { m, Offshore sailing, Kayaking, Jet skis, Jet boat, } \\
\text { Fixed keel boat, Canoeing, }\end{array}$ \\
\hline Non-aquatic activity & $\begin{array}{l}\text { The victim did not intend to be in the } \\
\text { water at the time of the incident, was } \\
\text { near or on the water or ice. }\end{array}$ & $\begin{array}{l}\text { Fall, Swept In, } \\
\text { Rock Fishing, } \\
\text { Swept away, } \\
\text { Rescue }\end{array}$ & $\begin{array}{l}\text { Non-aquatic } \\
\text { activity }\end{array}$ & $\begin{array}{l}\text { Accidental immersion, Flood/civil emergency, } \\
\text { Rescuing others }\end{array}$ \\
\hline $\begin{array}{l}\text { Non-aquatic } \\
\text { transport }\end{array}$ & $\begin{array}{l}\text { Operating (or a passenger in) any kind of } \\
\text { vehicle not intended for aquatic activity, } \\
\text { such as motor vehicles, snowmobiles, } \\
\text { aircraft etc. }\end{array}$ & $\begin{array}{l}\text { Non-aquatic } \\
\text { transport }\end{array}$ & $\begin{array}{l}\text { Land, ice or } \\
\text { air transportation }\end{array}$ & \\
\hline Other & $\begin{array}{l}\text { Unable to be classified in } \\
\text { other categories. }\end{array}$ & Other & & Other recreation \\
\hline Unknown & $\begin{array}{l}\text { Where activity immediately prior to } \\
\text { drowning is not known. }\end{array}$ & Unknown & Unknown & Unknown \\
\hline
\end{tabular}


(used to code to age group); sex; ethnicity; aquatic location category; activity prior to drowning; victim alcohol involvement; victim drug involvement; and resuscitation enacted - yes/no/unknown (Table 2).

There were 51 categories collected across the three countries for location of drowning (ranging from nine to 27). (Table 3 ) Activity being undertaken immediately prior to drowning was classified into 53 categories across the three countries. The number of activity categories ranged from six in Canada to 32 in New Zealand (Table 4).

A total of 8176 cases of unintentional fatal drowning occurred in the three countries (Australia 34.1\%, Canada 55.9\%, New Zealand 9.9\%). Crude fatal drowning rates per 100,000 population have been as low as 1.06 in Australia in 2014 and as high as 2.21 in New Zealand in 2008. When comparing the relative change between the first and the last year's drowning rates for each nation, all three have achieved reductions, with the highest reduction seen in New Zealand (-24.7\%) (Table 5).

The proportion of child drowning ranged from 12.1\% in Canada to $17.6 \%$ in Australia $\left(\mathrm{X}^{2}=46.4 ; p<0.001\right)$. There was no difference in the proportion of people aged over 50 years drowning by country (Table 6 ).

New Zealand (4.9\%) and Australia (4.7\%) recorded a significant proportion of fatal drownings among international tourists $\left(\mathrm{X}^{2}=28.9 ; p<0.001\right)$. Twenty-four percent $(23.9 \%)$ of drowning deaths in New Zealand were Indigenous peoples $\left(\mathrm{X}^{2}=195.6 ; p<0.001\right)$ (Table 6).

There were differences in locations of drowning in each country. Rivers were the leading location for drowning in Australia (27.1\%), lakes/ponds in Canada (36.4\%) and ocean/harbour locations in New Zealand (31.3\%). Australia was the only country to record a

Table 5 Resident crude drowning rates per 100,000 population by individual year, 10 year average and \% change, Australia, Canada and New Zealand

\begin{tabular}{llll}
\hline & Australia & Canada & New Zealand \\
\hline 2005 & 1.18 & 1.42 & 1.86 \\
2006 & 1.27 & 1.46 & 1.65 \\
2007 & 1.31 & 1.38 & 1.97 \\
2008 & 1.11 & 1.38 & 2.21 \\
2009 & 1.31 & 1.29 & 1.98 \\
2010 & 1.21 & 1.31 & 1.43 \\
2011 & 1.15 & 1.22 & 2.14 \\
2012 & 1.12 & 1.37 & 1.68 \\
2013 & 1.16 & 1.25 & 1.58 \\
2014 & 1.06 & 1.13 & 1.42 \\
10 year average & 1.19 & 1.32 & 1.79 \\
\% change (2014 vs 2005) & $-10.2 \%$ & $-20.4 \%$ & $-24.7 \%$ \\
\hline
\end{tabular}

Note: Drowning deaths of international tourists have been removed for the purposes of rate calculations statistically significant drowning burden in swimming pools $\left(\mathrm{X}^{2}=66.3 ; p<0.001\right)$ (Table 6).

Activity prior to drowning also varied, with aquatic activity common in Australia (28.4\%) and New Zealand $(43.7 \%)\left(\mathrm{X}^{2}=72.8 ; \mathrm{p}<0.001\right)$ and bathing $\left(9.6 \% ; \mathrm{X}^{2}=\right.$ $91.1 ; p<0.001)$ and boating-related incidents $(24.0 \%$; $\mathrm{X}^{2}=37.1 ; \mathrm{p}<0.001$ ) common in Canada (Table 6).

Alcohol was a common risk factor with known involvement in $36.0 \%$ of Canadian drownings and $25.8 \%$ of Australian drowning. Drugs were most commonly involved in Australia (27.0\%; $\left.\mathrm{X}^{2}=350.5 ; \mathrm{p}<0.001\right)$ and Canadian drowning fatalities (24.4\%). Pre-existing medical conditions were present in a similar proportion of cases in Australia $(37.2 \%)\left(\mathrm{X}^{2}=304.5 ; \mathrm{p}<0.001\right)$ and Canada (37.1\%) (Table 7).

Canada recorded the highest proportion of drowning deaths where lifejackets were not worn (67.4\%). Sixteen percent (15.7\%) of Canada's drowning fatalities during the study period occurred as a result of a MFE $\left(\mathrm{X}^{2}=\right.$ $67.7 ; \mathrm{p}<0.001$ ) (Table 7).

\section{Discussion}

Drowning prevention is a "wicked problem" [32] with a range of risk factors requiring targeted prevention strategies [33, 34]. Robust high-quality data underpins evidence for effective policy, interventions and education [34]. Currently there is a move across high-income countries to develop sophisticated drowning data systems $[1,11]$. This study compares the drowning data collection of three countries who have similar language, culture, aquatic engagement and drowning prevention. Better data collection systems should enable the creation of targeted and effective drowning prevention interventions. It is likely that, as systems grow, more variables will be collected. However, reliability and validity of these variables will need to be tested, and then likely reduced to a core set of important indicators, such as those suggested in the ILCOR Drowning Data Guideline [22], with local variation enabled to address specific challenges.

There currently exists no definitive guide to drowning data collection and coding variables (including subcategories). The ILCOR Drowning Data Guideline [22], although focusing on reporting data associated with drowning-related resuscitation, represents a useful first step. Six variables collected by countries within this study directly map to the ILCOR recommendation (five of which were able to be compared), however for those focused on drowning prevention, key variables required for the development of drowning prevention strategies are not discussed. For those countries focused on collecting and collating drowning data with a view to prevention, information on drowning causal factors is vital, including detail on aquatic location and activity being undertaken immediately prior to drowning. As a result, 
Table 6 Demographics, activity and location of fatal unintentional drowning, Australia, Canada and New Zealand

\begin{tabular}{|c|c|c|c|c|c|c|c|}
\hline & \multicolumn{2}{|c|}{ Australia } & \multicolumn{2}{|c|}{ Canada } & \multicolumn{2}{|c|}{ New Zealand } & \multirow[t]{2}{*}{$X^{2}$ ( $p$ value) } \\
\hline & $\mathrm{N}$ & $\%$ & $\mathrm{~N}$ & $\%$ & $\mathrm{~N}$ & $\%$ & \\
\hline Total & 2792 & 34.1 & 4572 & 55.9 & 812 & 9.9 & $118.349(p<0.001)$ \\
\hline \multicolumn{8}{|l|}{$\operatorname{Sex}(N=8176)$} \\
\hline Male & 2182 & 78.2 & 3715 & 81.3 & 669 & 82.4 & \multirow[t]{2}{*}{$13.027(p=0.001)$} \\
\hline Female & 610 & 21.8 & 857 & 18.7 & 143 & 17.6 & \\
\hline \multicolumn{8}{|l|}{ Age group $(n=8174)$} \\
\hline Children (0-17 years) & 492 & 17.6 & 555 & 12.1 & 138 & 17.0 & $46.431(p<0.001)$ \\
\hline Adults (18-64 years) & 1254 & 44.9 & 2220 & 48.6 & 376 & 46.3 & $9.622(p=0.008)$ \\
\hline Older people (65 years and older) & 1046 & 37.5 & 1795 & 39.3 & 298 & 36.7 & $3.470(p=0.176)$ \\
\hline \multicolumn{8}{|l|}{ International tourists $(\mathrm{N}=8176)$} \\
\hline Yes & 132 & 4.7 & 122 & 2.7 & 40 & 4.9 & \multirow[t]{2}{*}{$28.917(p<0.001)$} \\
\hline No & 2606 & 93.3 & 4426 & 96.8 & 706 & 86.9 & \\
\hline Unknown & 46 & 1.6 & 24 & 0.5 & 66 & 8.1 & - \\
\hline \multicolumn{8}{|l|}{ First Nations Peoples ( $N=8176$ ) } \\
\hline Yes & 156 & 5.6 & 503 & 11.0 & 194 & 23.9 & \multirow[t]{2}{*}{$195.631(p<0.001)$} \\
\hline No & 2232 & 79.9 & 4033 & 88.2 & 597 & 73.5 & \\
\hline Unknown & 382 & 13.7 & 36 & 0.8 & 21 & 2.6 & - \\
\hline \multicolumn{8}{|c|}{ Aquatic location of drowning incident $(N=8176)$} \\
\hline Bathtub & 203 & 7.3 & 444 & 9.7 & 40 & 4.9 & $27.655(p<0.001)$ \\
\hline Beach & 636 & 22.8 & 0 & 0.0 & 181 & 22.3 & $1150.963(p<0.001)$ \\
\hline Lake/Pond & 251 & 9.0 & 1665 & 36.4 & 72 & 8.9 & $826.485(p<0.001)$ \\
\hline Ocean/Harbour & 435 & 15.6 & 421 & 9.2 & 254 & 31.3 & $300.481(p<0.001)$ \\
\hline Other & 99 & 3.5 & 334 & 7.3 & 23 & 2.8 & $59.527(p<0.001)$ \\
\hline River & 756 & 27.1 & 1282 & 28.0 & 183 & 22.5 & $10.643(p=0.005)$ \\
\hline Swimming Pool & 412 & 14.8 & 423 & 9.3 & 59 & 7.3 & $66.262(p<0.001)$ \\
\hline Unknown & 0 & 0.0 & 3 & 0.1 & 0 & 0.0 & - \\
\hline \multicolumn{8}{|c|}{ Activity immediately prior to drowning $(\mathrm{N}=8176)$} \\
\hline Aquatic activity & 793 & 28.4 & 1171 & 25.6 & 355 & 43.7 & $72.757(p<0.001)$ \\
\hline Bathing & 201 & 7.2 & 437 & 9.6 & 0 & 0.0 & $91.064(p<0.001)$ \\
\hline Boating & 479 & 17.2 & 1098 & 24.0 & 167 & 20.6 & $37.105(p<0.001)$ \\
\hline Non-aquatic activity & 839 & 30.1 & 906 & 19.8 & 287 & 35.3 & $165.660(p<0.001)$ \\
\hline Non-aquatic transport & 183 & 6.6 & 740 & 16.2 & 0 & 0.0 & $266.668(p<0.001)$ \\
\hline Oher & 20 & 0.7 & 0 & 0.0 & 3 & 0.4 & $96.587(p<0.001)$ \\
\hline Unknown & 277 & 9.9 & 220 & 4.8 & 0 & 0.0 & - \\
\hline
\end{tabular}

the authors of this study propose a core minimum dataset of 11 variables including age, sex, location, activity, date of incident, primary cause of death and drug and alcohol involvement). Such variables are included based on a philosophy of data collection for drowning prevention and quality and availability of data. As countries become more sophisticated and drowning data collection matures, further variables can be added, however this core dataset should be maintained. Across the study period, 8176 cases of fatal, unintentional drowning were captured, with all three countries achieving reductions in crude drowning rates of at least $10 \%$. Detailed comparison across the three countries was challenging due to differing definitions, coding and data collected. It appears that the risk factors for drowning are similar across the countries with males (80.3\%), drugs (23.1\%), alcohol (30.6\%) and pre-existing medical conditions (35.3\%) contributing to the drowning burden. There were however, local variations between the datasets. For example Australia and New Zealand saw significant $(p<0.001)$ numbers in ocean/harbour and beach locations, whereas in Canada, drownings were more likely $(\mathrm{p}<0.001)$ to occur in lakes/ponds and bathtubs. 
Table 7 Alcohol, drugs, medical conditions, lifejacket wear, multiple fatality event, Australia, Canada and New Zealand

\begin{tabular}{|c|c|c|c|c|c|c|c|}
\hline & \multicolumn{2}{|c|}{ Australia } & \multicolumn{2}{|c|}{ Canada } & \multicolumn{2}{|c|}{ New Zealand } & \multirow[t]{2}{*}{$x^{2}$ ( $p$ value) } \\
\hline & $\overline{\mathrm{N}}$ & $\%$ & $\mathrm{~N}$ & $\%$ & $\mathrm{~N}$ & $\%$ & \\
\hline Total & 2792 & 34.1 & 4572 & 55.9 & 812 & 9.9 & $118.349(p<0.001)$ \\
\hline \multicolumn{8}{|c|}{ Alcohol involvement } \\
\hline Yes & 719 & 25.8 & 1647 & 69.0 & 133 & 16.4 & \multirow[t]{2}{*}{$106.674(p<0.001)$} \\
\hline No & 1203 & 43.1 & 2465 & 21.0 & 551 & 67.9 & \\
\hline Unknown & 729 & 26.1 & 460 & 10.1 & 128 & 15.8 & - \\
\hline \multicolumn{8}{|c|}{ Drug involvement } \\
\hline Yes & 755 & 27.0 & 1117 & 24.4 & 18 & 2.2 & \multirow[t]{2}{*}{$350.481(p<0.001)$} \\
\hline No & 1060 & 38.0 & 2397 & 52.4 & 666 & 82.0 & \\
\hline Unknown & 729 & 26.1 & 1058 & 23.1 & 128 & 15.8 & - \\
\hline \multicolumn{8}{|c|}{ Medical condition (pre-existing, chronic) } \\
\hline Yes & 1039 & 37.2 & 1698 & 37.1 & 153 & 18.8 & \multirow[t]{2}{*}{$304.496(p<0.001)$} \\
\hline No & 739 & 26.5 & 2694 & 58.9 & 492 & 60.6 & \\
\hline Unknown & 853 & 30.6 & 180 & 3.9 & 167 & 20.6 & - \\
\hline \multicolumn{8}{|c|}{ Lifejacket wear $(n=2039)$ \# } \\
\hline Yes & 42 & 9.4 & 210 & 15.8 & 51 & 19.1 & \multirow[t]{2}{*}{$2.099(p=0.350)$} \\
\hline No & 155 & 34.8 & 894 & 67.4 & 171 & 64.0 & \\
\hline Unknown & 249 & 55.8 & 222 & 16.7 & 45 & 16.9 & - \\
\hline \multicolumn{8}{|c|}{ Multiple Fatality Event } \\
\hline Yes & 254 & 9.1 & 717 & 15.7 & 90 & 11.1 & \multirow[t]{2}{*}{$67.703(p<0.001)$} \\
\hline No & 2528 & 90.5 & 3854 & 84.3 & 701 & 86.3 & \\
\hline Unknown & 10 & 0.4 & 1 & 0.0 & 21 & 2.6 & - \\
\hline
\end{tabular}

\#Boating only, excludes lifejackets worn in association with rock fishing and other activities where lifejackets are not applicable

For effective cross-country comparative studies, availability of quality data and comparable coding frameworks will be required, including coding hierarchy especially for cases where interpretation and therefore coding, could vary. Aside from basic drowning descriptors such as location and activity, all three countries collected rich information on risk and causal factors $[17,35]$ including data related to Indigenous peoples and lifejacket use. This suggests that all three countries identify Indigenous peoples as being at increased risk and lifejackets as an effective prevention strategy. With increased understanding of drowning risk factors, there will be an international need for minimum datasets and consistent coding.

Data quality poses a challenge for all undertaking epidemiological research. To help improve drowning data quality, there will be a need for engagement with the medico-legal process, including medical examiner, police and others involved in investigating drowning deaths. At a population level, ensuring the routine testing for, and collection of, data on presence of alcohol, drugs and preexisting medical conditions will be vital for evidencebased prevention efforts.
The comparison of drowning data between countries allows for identification of similarities in drowning risk and therefore effective prevention, as well as informing potential improvements in data collection and coding.

Calculation of country-specific drowning rates would exclude non-residents. However, there is increasing concern for, and a need to develop an understanding of, those who drown outside their country of residence. There are two broad groupings of people: (1) tourists; and (2) refugees, migrants and people without a fixed address. In Canada visitor status is not routinely collected and had to be derived for this study. Though often small numbers (international tourists account for $4 \%$ of drowning deaths in Australia [36]) they are a unique subset requiring different prevention strategies.

With increasing focus on drowning among refugees, migrants and stateless peoples [37-41], there is a unique challenge to calculate drowning rates worldwide. In Canada, during the study period three refugees drowned during a migration attempt and two illegal immigrants drowned. Drowning among non-residents is a challenge for prevention.

Collating and comparing data on sex and age group is reasonably straightforward whereas activity and location is more challenging. Within the three databases the number of categories within a variable differed, thus fidelity was lost, when merged. Detailed activity and location coding (i.e. greater than currently available in ICD-10 and more like what is proposed for ICD-11) will be critical for future international comparative studies. Alternative coding frameworks, such as that proposed by the International Classification of External Causes of Injury (ICECI) Coordination and Maintenance Group [42], provides greater detail and therefore more detailed evidence to support prevention efforts.

\section{Strengths and limitations}

A strength is the drowning data represents all cases of unintentional fatal drowning, beyond the narrow inclusion criteria based only on primary cause of death with an ICD code of W65-74, which has been found to underreport drowning $[1,3,43]$. This however, means that outside of the three countries included in this study, data is not comparable unless the same inclusion criteria is applied. The data is longitudinal, yet retrospective in nature and is drawn from the coronial system, allowing causal and risk factor analysis to be conducted. Data in this study is based on cause of death and not ICD-10 coding, and may therefore differ from official cause of death statistics.

Fatal drowning data from all three countries is coronial data and details for cases which are open (i.e. under investigation) may change. Only those variables where comparison was possible have been included in the study. Assumptions have been made when mapping location and 
activity variables. Those drowning victims with unknown residential status or those on work or student visas have been retained for the purposes of rate calculations.

\section{Conclusion}

Drowning is a global public health threat, impacting both high income and low and middle income countries. A total of 8176 drowning deaths were recorded across the study period, with all countries achieving at least a $10 \%$ reduction in country-level crude drowning rates across the 10 year period of the study. Among the data coding methodologies used by the three countries, there were 55 variables available for analysis of which, 19 were consistently collected and 13 were comparable. To compare the variables of location and activity, there was a need to merge categories, thus reducing the fidelity of data available. Future studies involving more countries will require work to enable comparisons to occur. The authors have identified 11 variables that would form a core minimum dataset, however there is a need for the development and validation of category definitions for location and activity variables that are consistently applied to allow for global comparison.

\section{Abbreviations \\ BAC: Blood Alcohol Concentration; DPRC: Drowning Prevention Research Centre; IBMSPSS: International Business Machines Statistical Package for the Social Sciences; ICD: International Classification of Diseases; ICECI: International Classification of External Causes of Injury; MFE: Multiple Fatality Event; NCIS: National Coronial Information System; NZHIS: New Zealand Health Information Service; WHO: World Health Organization; WSNZ: Water Safety New Zealand}

\section{Acknowledgements}

This research is supported by Royal Life Saving Society - Australia to aid in the reduction of drowning. Research at Royal Life Saving Society - Australia is supported by the Federal Government. This research is supported by The Drowning Prevention Research Centre - the lead agency for drowning and water incident research in Canada. New Zealand data and a portion of the open access costs were received through the kind cooperation and support of Water Safety New Zealand. The authors acknowledge the assistance of Mark Lindsay and Graeme Hamilton (Water Safety New Zealand) in sourcing the New Zealand data.

\section{Authors' contributions}

The study was conceptualised by authors AEP and RCF. Data for each country was compiled and analysed by author AEP. The manuscript was drafted by AEP with critical revision from authors RCF and TC. All authors approved the submitted version of the manuscript.

\section{Funding}

This study received no direct funding. The development of the Australian Database and this research is supported by Royal Life Saving Society Australia to aid in the reduction of drowning. Research at Royal Life Saving Society - Australia is supported by the Australian Government. The Canadian Database is supported by The Drowning Prevention Research Centre - the lead agency for drowning and water incident research in Canada. New Zealand data was received through the kind cooperation and support of Water Safety New Zealand. The authors acknowledge the assistance of Mark Lindsay and Graeme Hamilton (Water Safety New Zealand). Funding to publish this study open access was provided by Royal Life Saving Society Australia, James Cook University, the Canadian Drowning Prevention Research Centre and Water Safety New Zealand.

\section{Availability of data and materials}

Coronial data used in this study is not publicly available due to its sensitive nature. Therefore, the dataset supporting the findings in this study cannot be shared unless the person has obtained ethical approval due to the terms of the ethics agreement under which each of the country's data was approved (please see ethics approval and consent to participate section). Applications for access to the data can be made to apeden@rlssa.org.au (Australia), experts@drowningresearch.ca (Canada) and wsnz@watersafety.org. nz (New Zealand). The Canadian questionnaire is also not publicly available, but access can be requested by email: experts@drowningresearch.ca.

\section{Ethics approval and consent to participate}

Australia drowning data ethics is provided by the Victorian Department of Justice Human Research Ethic Committee (JHREC) (CF/07/13729; CF/10/ 25057; CF/13/19798). The Drowning Prevention Research Centre Canada has individual research agreements in place with the provincial and territorial coroner's and medical examiner's offices. Water Safety New Zealand has agreements with Coronial Services New Zealand, the National Coronial Information System (Australia) (NZ008) and the New Zealand Ministry of Health (2007-0825) to access data in order to maintain DrownBase. The protocols of DrownBase access adhere to the principles of the New Zealand Privacy Act 1993. Ethics approval for this comparative, multi-country study (covering data from Australia, Canada and New Zealand) was provided by James Cook University Human Research Ethics Committee (H7399). Consent to participate was not gained as data is de-identified, reflects people who are deceased and reported in an aggregated manner. As such consent to participate was not required by ethics committees who provided approval for this research.

\section{Consent for publication}

Not applicable.

\section{Competing interests}

The author's declare they have no competing interests.

\section{Author details}

${ }^{1}$ Royal Life Saving Society - Australia, PO Box 558, Broadway, New South Wales, Australia. ${ }^{2}$ College of Public Health, Medical and Veterinary Sciences, James Cook University, Townsville, Queensland, Australia. ${ }^{3}$ Drowning Prevention Research Centre Canada, Toronto, Canada.

Received: 19 December 2018 Accepted: 11 June 2019

Published online: 21 June 2019

\section{References}

1. Peden AE, Franklin RC, Mahony A, Barnsley P, Scarr J. Using a retrospective cross-sectional study to analyse unintentional fatal drowning in Australia: ICD-10 coding-based methodologies verses actual deaths. BMJ Open. 2017; 7:e019407. https://doi.org/10.1136/bmjopen-2017-019407.

2. Smith GS, Langley JD. Drowning surveillance: how well do E-codes identify submersion fatalities. Injury Prevention. 1998;4:135-9.

3. Passmore JW, Smith JO, Clapperton A. True burden of drowning: compiling data to meet the new definition. Int J Inj Control Saf Promot. 2007;14(1):1-3. https://doi.org/10.1080/17457300600935148.

4. Barss $\mathrm{P}$, Subait OM, Ali MHA, et al. Drowning in a high-income developing country in the Middle East: newspapers as an essential resource for injury surveillance. J Sci Med Sport. 2009;12(1):164-70. https://doi.org/10.1016/j. jsams.2007.08.016.

5. Işik $M$, Eşitti Ş. Content analysis of printed news media related to drowning incidents in Turkey. Hum Ecol Risk Assess. 2015;21(4):1050-61. https://doi. org/10.1080/10807039.2014.953373.

6. World Health Organization. Global report on drowning: preventing a leading killer. Geneva: World Health Organization; 2014.

7. World Health Organization. Preventing drowning: an implementation guide. Geneva: World Health Organization; 2017.

8. Peden AE, Franklin RC, Leggat PA. Fatal River drowning: identification of research gaps through a systematic literature review. Injury Prevention. 2016;22:202-9. https://doi.org/10.1136/injuryprev-2015-041750.

9. Franklin RC, Peden AE. Improving Pool fencing legislation in Queensland, Australia: attitudes and impact on child drowning fatalities. Int J Environ Res Public Health. 2017;14(12):1450. https://doi.org/10.3390/ijerph14121450. 
10. Mahony AJ, Peden AE, Franklin RC, et al. Fatal, unintentional drowning in older people: an assessment of the role of preexisting medical conditions. Healthy Aging Research. 2017;1:e7.

11. Clemens T, Tamim H, Rotondi M, et al. A population based study of drowning in Canada. BMC Public Health. 2016;16(1):559. https://doi.org/10. 1186/s12889-016-3221-8.

12. Franklin RC, Scarr JP, Pearn JH. Reducing drowning deaths: the continued challenge of immersion fatalities in Australia. MJA. 2010;192(3):123-6.

13. Peden $A E$, Franklin $\mathrm{RC}$, Pearn JH. Unintentional fatal child drowning in the bath: a 12-year Australian review (2002-2014). J Paediatr Child Health. 2018; 54(2):153-9. https://doi.org/10.1111/jpc.13688.

14. Prameprart M LA, Tongkumchum P. Modelling unintentional drowning mortality rates in Thailand, 2000-2009. Asia Pac J Public Health 2015;27(2): NP2471-NPNP79. doi: https://doi.org/10.1177/1010539513488796.

15. Rahman A, Giashuddin SM, Svanstrom L, et al. Drowning- a major but neglected child health problem in rural Bangladesh: implications for low income countries. Int J Inj Control Saf Promot. 2006;13(2):101-5.

16. Guevarra JP, Franklin RC, Basilio JA, et al. Child drowning prevention in the Philippines: the beginning of a conversation. Int J Inj Control Saf Promot. 2015;22(3):243-53. https://doi.org/10.1080/17457300.2014.912235.

17. Lozano R, Naghavi M, Foreman K, Lim S, Shibuya K, Aboyans V, et al. Global and regional mortality from 235 causes of death for 20 age groups in 1990 and 2010: a systematic analysis for the global burden of disease study 2010. Lancet. 2012;380(9859):2095-128.

18. Say L, Souza JP, Pattinson RC. Maternal near miss-towards a standard tool for monitoring quality of maternal health care. Best Pract Res Clin Obstet Gynaecol. 2009;23(3):287-96.

19. Cannon CP, Battler A, Brindis RG, Cox JL, Ellis SG, Every NR, ... \& Van De Werf FJ. American College of Cardiology key data elements and definitions for measuring the clinical management and outcomes of patients with acute coronary syndromes: a report of the American College of Cardiology Task Force on clinical data standards (acute coronary syndromes writing committee) endorsed by the American Association of Cardiovascular and Pulmonary Rehabilitation, American College of Emergency Physicians, American Heart Association, Cardiac Society of Australia \& New Zealand, National Heart Journal of the American College of Cardiology. 2001;38(7): 2114-30.

20. Mack K, Clapperton A, Macpherson A, Sleet D, Newton D, Murdoch J, Mackay JM, Berecki-Gisolf J, Wilkins N, Marr A, Ballesteros M, McClure R. Trends in the leading causes of injury mortality, Australia, Canada, and the United States, 2000-2014. 2017;108(2):7.

21. Lu T, Lunetta P, Walker S. Quality of cause-of-death reporting using ICD-10 drowning codes: a descriptive study of 69 countries. BMC Med Res Methodol. 2010;10(1):30.

22. Idris $A H$, JJLM, Bierens GD, Perkins $V$, Wenzel V, Nadkarni P, Morley D, et al. 2015 Revised Utstein-Style Recommended Guidelines for Uniform Reporting of Data From Drowning-Related Resuscitation: An ILCOR Advisory Statement. Circ Cardiovasc Qual Outcomes. 2017;10(7):e000024.

23. Bugeja L, Ibrahim JE, Ferrah $\mathrm{N}$, et al. The utility of medico-legal databases for public health research: a systematic review of peer-reviewed publications using the National Coronial Information System. Health Res Policy Syst. 2016;14(1). https://doi.org/10.1186/s12961-016-0096-1.

24. Royal Life Saving Society - Australia. Royal Life Saving National Fatal Drowning Database Sydney, 2002/03 to 2016/17. Available from: https:// www.royallifesaving.com.au/facts-and-figures/research-and-reports/royal-lifesaving-national-fatal-drowning-database. Accessed 16 Dec 2018.

25. Royal Life Saving Society - Australia. Royal Life Saving National Drowning Report 2017: Royal Life Saving Society - Australia, 2017.

26. van Beeck EF, Branche CM, Szpilman D, et al. A new definition of drowning: towards documentation and prevention of a global public health problem. Bull World Health Organ. 2005;83(11):853-6.

27. Water Safety New Zealand. Drowning statistics. 2018. Available from: https:// watersafety.org.nz/Drowning\%20Statistics. Accessed 16 Dec 2018

28. SPSS Inc. IBM SPSS Statistics 20.0.0. Chicago: IBM; 2010

29. Australian Bureau of Statistics. 3101.0 - Australian demographic statistics, September 2017. Canberra: Australian Bureau of Statistics; 2018. Available from: http://www.abs.gov.au/AUSSTATS/abs@.nsf/DetailsPage/3101. 0Sep\%202017? OpenDocument. Accessed 4 July 2018.

30. Stats NZ. Stats NZ Infoshare 2018. Available from: http://archive.stats.govt. nz/infoshare/NiewTable.aspx?pxID=35b8fa52-ca19-4b97-b23b-1f5aabdb1dad. Accessed 4 July 2018.
31. Statistics Canada. Population estimates, quarterly - Table 17-10-0009-01 2018. Available from: https://www150.statcan.gc.ca/n1//en/type/data?MM=1. Accessed 4 July 2018.

32. Brown VA, Harris JA, Russell JY, editors. Tackling wicked problems through the transdicplinary imagination: Earthscan; 2010.

33. Bugeja L, Franklin RC. An analysis of stratagems to reduce drowning deaths of young children in private swimming pools and spas in Victoria, Australia. Int J Inj Control Saf Promot. 2012:1-13.

34. Pearn JH, Nixon JW, Franklin RC, et al. Safety legislation, public health policy and drowning prevention. Int J Inj Control Saf Promot. 2008;15(2):122-3.

35. Peden $A E$, Franklin RC, Leggat PA. Preventing river drowning deaths: lessons from coronial recommendations. Health Promot J Austr. 2018;29(2):144-52. https://doi.org/10.1002/hpja.24

36. Peden $A E$, Franklin RC, Leggat PA. International travelers and unintentional fatal drowning in Australia - a 10 year review 2002-12. J Travel Med. 2016; 23(2):1-7. https://doi.org/10.1093/jtm/tav031.

37. Embury-Dennis T. At least 90 refugees feared drowned after boat capsizes off coast of Libya. Independent. 2018.

38. MEE and Agencies. At least 8,500 refugees drowned on way to Europe since death of Alan Kurdi. Middle East Eye. 2017.

39. Carling J. Migration control and migrant fatalities at the Spanish-African Borders. Int Migr Rev. 2007;41(2):316-43. https://doi.org/10.1111/j.1747-7379. 2007.00070.x

40. Perkowski N. Deaths, interventions, humanitarianism and human rights in the Mediterranean 'migration crisis'. Mediterranean Politics. 2016;21(2):331-5. https://doi.org/10.1080/13629395.2016.1145827.

41. Beerman S, Bean E, Byers B, Graham D, Kurdi T, Miller D, Peden AE, Quan L, Scarr J, Sindall R. Vancouver declaration on drowning risk reduction of migrants and refugees. Available from: http://www.wcdp2017.org/ conference-statements. Accessed 18 June 2019.

42. ICECI Coordination and Management Group. International classification of external causes of injuries (ICECI) version 1.2. Adelaide: consumer safety institute Amsterdam and AlHW National Injury Surveillance Unit, 2004.

43. Lunetta P, Penttilä A, Sajantila A. Drowning in Finland: "external cause" and "injury" codes. Inj Prev. 2002;8:342-4.

\section{Publisher's Note}

Springer Nature remains neutral with regard to jurisdictional claims in published maps and institutional affiliations.

\section{Ready to submit your research? Choose BMC and benefit from:}

- fast, convenient online submission

- thorough peer review by experienced researchers in your field

- rapid publication on acceptance

- support for research data, including large and complex data types

- gold Open Access which fosters wider collaboration and increased citations

- maximum visibility for your research: over $100 \mathrm{M}$ website views per year

At $\mathrm{BMC}$, research is always in progress.

Learn more biomedcentral.com/submission 